\title{
Association of soft tissue infection in the extremity with glucose and lipid metabolism and inflammatory factors
}

\author{
HAIJUN SUN* ${ }^{*}$ XIUYUN ZHANG* ${ }^{*}$ WEI SHI and BO FANG \\ Department of Orthopedics, Dongying People's Hospital, Dongying, Shandong 257000, P.R. China
}

Received June 11, 2018; Accepted January 11, 2019

DOI: $10.3892 /$ etm.2019.7232

\begin{abstract}
Association of soft tissue infection in the extremity with glucose and lipid metabolism as well as inflammatory factors was investigated. One hundred and twenty-six patients with diabetes mellitus (DM) complicated with soft tissue infection in the lower extremity admitted and treated in Dongying People's Hospital from March 2016 to February 2017 were selected and divided into mild $(n=46)$, moderate $(n=43)$ and severe group $(n=37)$ according to the severity of the soft tissue infection in the lower extremity. The glucose and lipid metabolism, inflammatory factors and influencing factors were compared among different groups of patients before treatment, and the changes in glucose and lipid metabolism as well as inflammatory factors were observed after treatment. Before treatment, the levels of free fatty acid (FFA), fasting plasma glucose (FPG), fasting insulin (FINS), vascular cell adhesion molecule-1 (VCAM-1), C-reactive protein (CRP), tumor necrosis factor-alpha (TNF- $\alpha$ ) and interleukin- 6 (IL-6) in mild group were remarkably lower than those in moderate and severe groups, while the serum adiponectin (APN) level was obviously higher $(\mathrm{P}<0.05)$. Logistic regression analysis indicated that FFA, FPG, FINS, APN, VCAM-1, CRP, TNF- $\alpha$ and IL- 6 were risk factors influencing soft tissue infection in the extremity $(\mathrm{P}<0.05)$. After treatment, among the 126 patients, the levels of FFA, FPG, FINS, VCAM-1, CRP, TNF- $\alpha$ and IL- 6 were decreased markedly, while the APN level was increased evidently $(\mathrm{P}<0.05)$. Compared with patients innon-toe/extremity amputation group, patients in toe/extremity amputation group had elevated levels of FFA, FPG, FINS, VCAM-1, CRP, TNF- $\alpha$ and IL- 6 as well as declined APN level $(\mathrm{P}<0.05)$. Glucose and lipid metabolism
\end{abstract}

Correspondence to: Dr Bo Fang, Department of Orthopedics, Dongying People's Hospital, 317 Nanyi Road, Dongying, Shandong 257000, P.R. China

E-mail: fugu7007@126.com

*Contributed equally

Key words: soft tissue infection in the extremity, diabetes mellitus, glucose and lipid metabolism, inflammatory factors and inflammatory factors are closely related to soft tissue infection in the extremity.

\section{Introduction}

Diabetes mellitus (DM), a common type of disorder of glucose metabolism, is a chronic non-communicable disease ranking next to cardiovascular disease that poses great threat to human health (1). With the development of China's economy and improvement of people's living standard, as one of the public health problems around the globe at present, DM cases are increasing year by year, and it is expected that there will be up to 500 million DM patients globally by 2030 (2). DM has many complications, of which diabetic foot (DF) is a fairly serious one. Destruction and infection of the soft tissues at the end of foot of DF patients caused by invasion of pathogenic microorganisms, if not treated actively and effectively, can increase the difficulty in treatment and even lead to toe/extremity amputation and death of the patients in severe cases (3). In-depth study on the pathogenesis of soft tissue infection in the extremity of DM patients and searching for effective treatment methods are of great significance in prevention and treatment of DF. Since there are few reports on the associations of soft tissue infection in the extremity with glucose and lipid metabolism as well as inflammatory factors, this research aims to explore these associations and provide a basis for DF prevention by elaborating and analyzing the changes in glucose and lipid metabolism and inflammatory factors in DM patients complicated with soft tissue infection in the lower extremity.

\section{Patients and methods}

General data. A total of $126 \mathrm{DM}$ patients complicated with soft tissue infection in the lower extremity admitted and treated in Dongying People's Hospital from March 2016 to February 2017 were selected. Inclusion criteria were: i) Patients meeting diagnostic criteria of DM (4), ii) patients who were definitely diagnosed with bacterial infection through bacterial culture of specimens obtained from soft tissues in the lower extremity, and iii) patients who signed the informed consent. Exclusion criteria were: i) Patients with liver and kidney failure and ii) patients with malignant tumors. The general data of the patients are shown in Table I.

The study was approved by the Ethics Committee of Dongying People's Hospital (Dongying, China). Patients who 
Table I. General data of the patients.

\begin{tabular}{lc}
\hline Characteristics & No. of patients $(\mathrm{n}=126)$ \\
\hline Male [n (\%)] & $61(48.41)$ \\
Female [n (\%)] & $64(51.59)$ \\
Age (years) & $30-78$ \\
Average age (years) & $53.38 \pm 8.43$ \\
BMI $\left(\mathrm{kg} / \mathrm{m}^{2}\right)$ & $24.84 \pm 3.28$ \\
Degree of infection & \\
Mild & $46(36.51)$ \\
Moderate & $43(34.13)$ \\
Severe & $37(29.37)$ \\
\hline
\end{tabular}

BMI, body mass index.

participated in this research had complete clinical data. The signed informed consents were obtained from the patients or the guardians.

Data collection, diagnosis and treatment. The background information (including demographic characteristics as well as family, economic and living data) and disease information of the 126 patients were collected. The infected areas of the patients were cleaned with $0.9 \%$ sodium chloride solution, and then specimens were scrapped from the base of the wound using a sterile cotton swab. After bacterial culture, the strains were identified by virtue of a VITEK32 Automatic Microbiology Analyzer (bioMérieux, Marcy-l'Étoile, France), so as to determine the infection and its degree and conduct targeted treatment with antimicrobial agents or other methods. The patients were followed up for 1 year to observe the variations in related indexes to the patients' glucose and lipid metabolism and inflammatory factors.

Detection of related indexes. A total of $5 \mathrm{ml}$ fasting venous blood (fasted for $8 \mathrm{~h}$ ) was drawn in the morning from each patient before and after treatment, respectively, followed by centrifugation at $2,600 \mathrm{x}$ g for $15 \mathrm{~min}$ at $20^{\circ} \mathrm{C}$. Next, the supernatant was taken and preserved in a refrigerator at $-80^{\circ} \mathrm{C}$ for standby use.

The patients' fasting plasma glucose (FPG) was measured via glucose oxidase method, and the level of fasting insulin (FINS) was detected using radioimmunoassay. Oxidase method was adopted to determine triglyceride (TG), and colorimetry was applied to measure free fatty acid (FFA). Relevant kits were purchased from Nanjing Jiancheng Bioengineering Institute (Nanjing, China), and the operations were conducted in strict accordance with the kit instructions.

Enzyme-linked immunosorbent assay (ELISA) was performed to detect the concentrations of adiponectin (APN), vascular cell adhesion molecule-1 (VCAM-1), C-reactive protein (CRP), tumor necrosis factor-alpha (TNF- $\alpha$ ) and interleukin-6 (IL-6) in the serum, to which related kits were provided by Nanjing Jiancheng Bioengineering Institute. The operations were conducted strictly according to the instructions. The optical density (OD) was read at the wavelength of $450 \mathrm{~nm}$ by means of a microplate reader
(Bio-Rad, Hercules, CA, USA) and the concentrations of corresponding sample APN, VCAM-1, CRP, TNF- $\alpha$ and IL-6 were calculated.

\section{Evaluation of indexes}

Infection degree (5). i) Mild infection: The infection was only limited to the skin and subcutaneous tissues, with local fever, redness and swelling, pain, suppuration and diameter of redness and swelling at the ulcer margin $<2 \mathrm{~cm}$, and the patients had no complications. ii) Moderate infection: The infection spread to fascia or deep tissues, with abscess and gangrene affecting the joints, skeletons, muscles and tendons. iii) Severe infection: The patients had unstable metabolism, complicated with systemic toxemia.

The FPG level of the patients was measured via glucose oxidase method, the FINS level was detected through radioimmunoassay and immunofluorescence assay, and the FFA level was determined using colorimetry. ELISA was applied to measure the levels of APN, VCAM-1, CRP, TNF- $\alpha$ and IL-6. Relevant kits were purchased from Nanjing Jiancheng Bioengineering Institute.

Statistical analysis. Statistical Product and Service Solutions (SPSS) 19.0 software (SPSS Inc., Chicago, IL, USA) was utilized to process the data. Measurement data were presented as mean \pm standard deviation (mean $\pm \mathrm{SD}$ ), and t-test was conducted. Logistic regression analysis was performed on influencing factors between groups. ANOVA was used for comparison between multiple groups and the post hoc test was LSD test. $\mathrm{P}<0.05$ was considered to indicate a statistically significant difference.

\section{Results}

Comparison of glucose and lipid metabolism before treatment among three groups of patients. Before treatment, the levels of FFA, FPG and FINS in mild group were remarkably lower than those in moderate and severe groups, while the APN level was obviously higher $(\mathrm{P}<0.05)($ Table II).

Comparison of indexes for serum inflammatory factors before treatment among three groups of patients. Compared with those in moderate and severe groups, before treatment, the levels of VCAM-1, CRP, TNF- $\alpha$ and IL-6 in mild group were reduced notably $(\mathrm{P}<0.05)$ (Table III).

Analysis of influencing factors for soft tissue infection in the extremity of patients. With the occurrence of soft tissue infection in the extremity as a dependent variable, and FFA, FPG, FINS, VCAM-1, CRP, TNF- $\alpha$ and IL- 6 as independent variables, the results of logistic regression analysis indicated that FFA, FPG, FINS, APN, VCAM-1, CRP, TNF- $\alpha$ and IL-6 were independent risk factors for soft tissue infection in the lower extremity of patients $(\mathrm{P}<0.05)$ (Table IV).

Comparison of glucose and lipid metabolism before and after treatment among 126 patients. After treatment, the levels of FFA, FPG and FINS in the patients were decreased significantly, while the APN level was elevated remarkably $(\mathrm{P}<0.05)$ (Table V). 
Table II. Comparison of indexes for glucose and lipid metabolism among three groups.

\begin{tabular}{|c|c|c|c|c|c|}
\hline Groups & $\mathrm{n}$ & FFA (mmol/l) & FPG $(\mathrm{mmol} / \mathrm{l})$ & FINS $(\mu \mathrm{IU} / \mathrm{ml})$ & APN (mg/l) \\
\hline Mild & 46 & $0.68 \pm 0.12$ & $7.87 \pm 0.56$ & $11.52 \pm 2.15$ & $15.53 \pm 2.32$ \\
\hline Moderate & 43 & $0.85 \pm 0.23^{\mathrm{a}, \mathrm{b}}$ & $9.83 \pm 0.63^{\mathrm{a}, \mathrm{b}}$ & $16.25 \pm 2.36^{\mathrm{a}, \mathrm{b}}$ & $8.27 \pm 1.56^{\mathrm{a}, \mathrm{b}}$ \\
\hline Severe & 37 & $0.97 \pm 0.26^{\mathrm{a}}$ & $10.26 \pm 0.47^{\mathrm{a}}$ & $20.74 \pm 2.38^{\mathrm{a}}$ & $6.32 \pm 1.24^{\mathrm{a}}$ \\
\hline
\end{tabular}

${ }^{a} \mathrm{P}<0.05$ vs. mild group, ${ }^{\mathrm{b}} \mathrm{P}<0.05$ vs. severe group. FFA, free fatty acid; FPG, fasting plasma glucose; FINS, fasting insulin; APN, adiponectin.

Table III. Comparison of indexes for serum inflammatory factors among three groups.

\begin{tabular}{|c|c|c|c|c|c|}
\hline Groups & $\mathrm{n}$ & VCAM-1 (ng/ml) & $\mathrm{TNF}-\alpha(\mathrm{pg} / \mathrm{ml})$ & CRP (mg/l) & IL-6 (pg/ml) \\
\hline Mild & 46 & $0.68 \pm 0.12$ & $7.87 \pm 0.56$ & $11.52 \pm 2.15$ & $15.53 \pm 2.32$ \\
\hline Moderate & 43 & $0.85 \pm 0.23^{\mathrm{a}, \mathrm{b}}$ & $9.83 \pm 0.63^{a, b}$ & $16.25 \pm 2.36^{\mathrm{a}, \mathrm{b}}$ & $8.27 \pm 1.56^{\mathrm{a}, \mathrm{b}}$ \\
\hline Severe & 37 & $0.97 \pm 0.26^{\mathrm{a}}$ & $10.26 \pm 0.47^{\mathrm{a}}$ & $20.74 \pm 2.38^{\mathrm{a}}$ & $6.32 \pm 1.24^{\mathrm{a}}$ \\
\hline
\end{tabular}

${ }^{\mathrm{a}} \mathrm{P}<0.05$ vs. mild group, ${ }^{\mathrm{b}} \mathrm{P}<0.05$ vs. severe group. VCAM-1, vascular cell adhesion molecule-1; TNF- $\alpha$, tumor necrosis factor- $\alpha$; CRP, C-reactive protein; IL-6, interleukin-6.

Table IV. Logistic regression analysis of factors influencing soft tissue infection in the lower extremity.

\begin{tabular}{|c|c|c|c|c|c|c|}
\hline Factor & $\beta$ value & SE & Wald & OR & $95 \% \mathrm{CI}$ & P-value \\
\hline FFA & 0.731 & 0.532 & 5.783 & 1.323 & $1.075-2.952$ & 0.005 \\
\hline FPG & 0.637 & 0.517 & 5.372 & 1.213 & $1.007-2.759$ & 0.023 \\
\hline FINS & 0.867 & 0.673 & 5.421 & 1.815 & $1.106-3.854$ & 0.017 \\
\hline VCAM-1 & 0.635 & 0.804 & 6.425 & 1.936 & $1.096-2.542$ & 0.008 \\
\hline CRP & 0.326 & 0.649 & 5.753 & 1.323 & $1.075-2.212$ & 0.006 \\
\hline TNF- $\alpha$ & 0.633 & 0.717 & 4.524 & 1.815 & $1.103-2.347$ & 0.018 \\
\hline IL-6 & 0.815 & 0.486 & 5.292 & 1.546 & $1.025-2.973$ & 0.043 \\
\hline
\end{tabular}

SE, standard error; OR, odds ratio; CI, confidence interval; TNF- $\alpha$, tumor necrosis factor- $\alpha$.

Table V. Comparison of glucose and lipid metabolism before and after treatment among 126 patients.

\begin{tabular}{lccrr}
\hline Time & FFA $(\mathrm{mmol} / \mathrm{l})$ & FPG $(\mathrm{mmol} / \mathrm{l})$ & FINS $(\mu \mathrm{IU} / \mathrm{ml})$ & APN $(\mathrm{mg} / \mathrm{l})$ \\
\hline Before treatment & $0.86 \pm 0.24$ & $9.07 \pm 0.53$ & $20.52 \pm 2.34$ & $6.94 \pm 1.38$ \\
After treatment & $0.61 \pm 0.16$ & $6.83 \pm 0.48$ & $14.24 \pm 2.26$ & $14.58 \pm 2.26$ \\
t value & 9.729 & 35.164 & 21.669 & 32.386 \\
P-value & $<0.001$ & $<0.001$ & $<0.001$ & $<0.001$ \\
\hline
\end{tabular}

FFA, free fatty acid; FPG, fasting plasma glucose; FINS, fasting insulin; APN, adiponectin.

Comparison of inflammatory factors before and after treatment among 126 patients. The levels of VCAM-1, CRP, TNF- $\alpha$ and IL- 6 in the patients were obviously reduced after treatment $(\mathrm{P}<0.05)$ (Table VI).

Comparison of glucose and lipid metabolism after 1-year follow-up between toelextremity amputation and non-toel extremity amputation group. Compared with toe/extremity amputation group, non-toe/extremity amputation group had markedly decreased FFA, FPG and FINS levels, as well as increased APN level $(\mathrm{P}<0.05)$ (Table VII).

Comparison of inflammatory factors after 1-year follow-up between toelextremity amputation group and non-toelextremity amputation group. The levels of VCAM-1, CRP, TNF- $\alpha$ and IL- 6 in non-toe/extremity amputation group were significantly lower than those in toe/extremity amputation group $(\mathrm{P}<0.05)$ (Table VIII). 
Table VI. Comparison of indexes for inflammatory factors before and after treatment among 126 patients.

\begin{tabular}{|c|c|c|c|c|}
\hline Time & VCAM-1 (ng/ml) & $\mathrm{TNF}-\alpha(\mathrm{pg} / \mathrm{ml})$ & CRP (mg/l) & IL-6 (pg/ml) \\
\hline Before treatment & $882.57 \pm 33.52$ & $23.46 \pm 3.56$ & $4.06 \pm 0.64$ & $10.56 \pm 2.34$ \\
\hline After treatment & $668.68 \pm 27.36$ & $11.65 \pm 2.63$ & $1.78 \pm 0.23$ & $3.28 \pm 1.26$ \\
\hline $\mathrm{t}$ value & 55.489 & 29.951 & 37.633 & 30.748 \\
\hline P-value & $<0.001$ & $<0.001$ & $<0.001$ & $<0.001$ \\
\hline
\end{tabular}

VCAM-1, vascular cell adhesion molecule-1; TNF- $\alpha$, tumor necrosis factor- $\alpha$; CRP, C-reactive protein; IL-6, interleukin-6.

Table VII. Comparison of glucose and lipid metabolism between two groups.

\begin{tabular}{|c|c|c|c|c|c|}
\hline Groups & $\mathrm{n}$ & FFA (mmol/l) & FPG (mmol/l) & FINS $(\mu \mathrm{IU} / \mathrm{ml})$ & $\mathrm{APN}(\mathrm{mg} / \mathrm{l})$ \\
\hline Toe/extremity amputation & 38 & $0.97 \pm 0.22$ & $11.47 \pm 0.86$ & $26.76 \pm 3.34$ & $5.46 \pm 0.34$ \\
\hline Non-toe/extremity amputation & 88 & $0.63 \pm 0.16$ & $7.23 \pm 0.65$ & $12.28 \pm 2.25$ & $14.78 \pm 1.67$ \\
\hline t value & & 8.596 & 27.220 & 24.437 & 50.008 \\
\hline P-value & & $<0.001$ & $<0.001$ & $<0.001$ & $<0.001$ \\
\hline
\end{tabular}

FFA, free fatty acid; FPG, fasting plasma glucose; FINS, fasting insulin; APN, adiponectin.

Table VIII. Comparison of inflammatory factors between two groups.

\begin{tabular}{|c|c|c|c|c|c|}
\hline Groups & $\mathrm{n}$ & VCAM-1 (ng/ml) & $\mathrm{TNF}-\alpha(\mathrm{pg} / \mathrm{ml})$ & $\mathrm{CRP}(\mathrm{mg} / \mathrm{l})$ & IL-6 (pg/ml) \\
\hline Toe/extremity amputation & 38 & $1212.58 \pm 65.52$ & $30.47 \pm 2.56$ & $9.56 \pm 1.32$ & $26.63 \pm 3.35$ \\
\hline Non-toe/extremity amputation & 88 & $768.58 \pm 36.54$ & $10.65 \pm 1.63$ & $2.36 \pm 1.08$ & $4.54 \pm 1.32$ \\
\hline t value & & 39.223 & 44.028 & 32.063 & 39.351 \\
\hline P-value & & $<0.001$ & $<0.001$ & $<0.001$ & $<0.001$ \\
\hline
\end{tabular}

VCAM-1, vascular cell adhesion molecule-1; TNF- $\alpha$, tumor necrosis factor- $\alpha$; CRP, C-reactive protein; IL-6, interleukin-6.

\section{Discussion}

DM mostly occurs in middle-aged and elderly people, and it has a relatively high incidence rate in the patients with soft tissue infection in the extremity because of their poor autoimmunity plus local inadequate blood supply resulting from long-term glucose control (6). Due to low anti-infection ability and long-term impacts of hyperglycemia, metabolism dysfunction and certain degrees of damage to immune system occur in the DM patients, leading to declined chemotaxis, adhesion and phagocytosis of monocytes and neutrophils in the body and decreased resistance to invasion of various pathogens. In addition, the elevated contents of carbohydrates and proteins in the exudates of injured soft tissues are beneficial to the survival and reproduction of bacteria, which extremely easily trigger soft tissue infection in the extremity, especially the feet $(7,8)$. Large number of studies have demonstrated that the pathogens of infection are dominated by Gram-negative bacteria possessing strong drug resistance (9). Defects of the soft tissue in the extremity of DF patients heal more slowly than those in other parts because they are located far away from the heart and have less collateral circulation and blood supply than other parts. Once the infection occurs, it is more difficult to be cured. If active and effective treatments are not applied, it will even cause toe/extremity amputation, so it is very important to prevent and treat soft tissue infection in the extremity of DF patients (10).

The treatment of soft tissue infection in the extremity of DF patients may involve multiple disciplines, and forming a complete therapy system by integrating glucose control with neural nourishment, blood supply improvement, infection control and surgical intervention is crucial to positively prevent and treat the infection. APN is a type of adipocytokine possessing insulin-sensitizing effects, as well as the functions of lowering glucose, ameliorating insulin resistance and resisting inflammation, so it plays a vital role in the immunity and inflammatory responses in the body (11). FFA, as a kind of non-esterified fatty acid and an intermediate product of lipid metabolism, is synthesized by the lipid structure of the cell membrane and prostaglandin, which belongs to the important energy substances of human body (12). APN has a negative regulatory effect on inflammation, which suppresses the mature macrophages, as well as the growth of their precursor, 
and prevents the chronic persistence of inflammation (13). FINS can promote the synthesis of fats by the adipocytes and improve the activity of lipoprotein lipase, thereby accelerating the generation of FFA, further affecting pancreatic $\beta$-cells, triggering insulin resistance, elevating FPG level in the patients, causing disorder of glucose metabolism, increasing output of glucose from the liver and inducing raised content of carbohydrates and proteins in the exudates of soft tissues in the extremity, which can provide an excellent living environment for a variety of pathogens and exacerbate the degree of infection (14). The results of this research manifested that the higher the FFA, FPG and FINS levels were, the more severe the infection in the patients would be. As the APN level was reduced, the anti-inflammatory capacity of the patients declined, while the infection was aggravated. After in-time treatment, the levels of FFA, FPG and FINS were decreased, the APN level was increased, and the infection as well as toe/extremity amputation rate of the patients was effectively controlled, which were conducive to prognosis.

As an immunoglobulin, VCAM-1 can participate in the processes of immunoregulation and inflammatory response and act as a marker of endothelial injury (15). TNF- $\alpha$ is the first inflammatory mediator produced in the body, and it exerts crucial functions of causing inflammatory responses, antiinfection and host defense (16). IL-6, a type of lymphocyte factor of acute phase reaction, is able to induce adhesion and aggregation of inflammatory cells, so as to promote inflammation (17). CRP is an acute-phase reaction protein, which is regarded as a marker reflecting the degree of inflammatory response in clinic due to its simple and rapid detection methods (18). It was indicated in this research that the levels of VCAM-1, CRP, TNF- $\alpha$ and IL- 6 were on the rise as the degree of infection was increased. However, the levels of those inflammatory factors declined after active treatment, and the patients had good prognosis. The reason is that VCAM-1 at a high concentration can result in difficulty in healing damaged soft tissues in the extremity and mediate the inflammatory responses by increasing the synthesis, release and other mechanisms of tissue factor in the endothelial cells. Moreover, along with the exacerbation of infection, the inflammatory responses lost control in both intensity and time limitation, thus increasing the expression of TNF- $\alpha$, CRP and IL-6 and decreasing the sensitivity of the body to insulin (19). Peripheral blood mononuclear cells at a high glucose level are capable of generating a large amount of inflammatory factors, forming combined effects, inducing insulin resistance and leading to lowered tissue repair capacity. It is the mechanism for the difficulty in healing wounds, and it is an important reason for progression and deterioration of the disease as well as rising amputation rate (20). Therefore, glucose and lipid metabolism and inflammatory factors are also the independent risk factors for soft tissue infection in the lower extremity.

In conclusion, glucose and lipid metabolism, together with inflammatory factors, is the risk factor influencing soft tissue infection in the extremity. High levels of FPG, glucose and lipid metabolism and inflammatory factors exert vital effects on the occurrence and aggravation of soft tissue infection in the extremity. More attention should be paid to anti-inflammatory therapy during treatment, so as to decrease the toe/extremity amputation rate.

\section{Acknowledgements}

Not applicable.

\section{Funding}

No funding was received.

\section{Availability of data and materials}

The datasets used and/or analyzed during the current study are available from the corresponding author on reasonable request.

\section{Authors' contributions}

HS drafted the manuscript. HS and XZ recorded and analyzed the general data of patients and contributed to the conception and design of the work. WS detected related indexes. BF was responsible for ELISA.All authors read and approved the final manuscript.

\section{Ethics approval and consent to participate}

The study was approved by the Ethics Committee of Dongying People's Hospital (Dongying, China). Patients who participated in this research had complete clinical data. The signed informed consents were obtained from the patients or the guardians.

\section{Patient consent for publication}

Not applicable.

\section{Competing interests}

The authors declare that they have no competing interests.

\section{References}

1. Rossi G; American Diabetes Association: Diagnosis and classification of diabetes mellitus. Recenti Prog Med 101: 274-276, 2010 (In Italian).

2. Colagiuri S: Glycated haemoglobin (HbAlc) for the diagnosis of diabetes mellitus - practical implications. Diabetes Res Clin Pract 93: 312-313, 2011.

3. Al-Rubeaan K, Al Derwish M, Ouizi S, Youssef AM, Subhani SN, Ibrahim HM and Alamri BN: Diabetic foot complications and their risk factors from a large retrospective cohort study. PLoS One 10: $\mathrm{e} 0124446,2015$.

4. Klenerman L, McCabe C, Cogley D, Crerand S, Laing P and White M: Screening for patients at risk of diabetic foot ulceration in a general diabetic outpatient clinic. Diabet Med 13: 561-563, 1996.

5. Lavigne JP, Sotto A, Dunyach-Remy C and Lipsky BA: New molecular techniques to study the skin microbiota of diabetic foot ulcers. Adv Wound Care (New Rochelle) 4: 38-49, 2015.

6. Hingorani A, LaMuraglia GM, Henke P, Meissner MH, Loretz L, Zinszer KM, Driver VR, Frykberg R, Carman TL, Marston W, et al: The management of diabetic foot: A clinical practice guideline by the Society for Vascular Surgery in collaboration with the American Podiatric Medical Association and the Society for Vascular Medicine. J Vasc Surg 63 (Suppl): S3-S21, 2016

7. Pickwell K, Siersma V, Kars M, Apelqvist J, Bakker K, Edmonds M, Holstein P, Jirkovská A, Jude E, Mauricio D, et al: Predictors of lower-extremity amputation in patients with an infected diabetic foot ulcer. Diabetes Care 38: 852-857, 2015. 
8. Klenerman L, Mccabe C, Cogley D, Crerand S, Laing P and White M: Screening for patients at risk of diabetic foot ulceration in a general diabetic outpatient clinic. Diabetic Med 13: 561-563, 2015.

9. Stappers MH, Hagen F, Reimnitz P, Mouton JW, Meis JF and Gyssens IC: Direct molecular versus culture-based assessment of Gram-positive cocci in biopsies of patients with major abscesses and diabetic foot infections. Eur J Clin Microbiol Infect Dis 34 1885-1892, 2015

10. Tennvall GR, Apelqvist $\mathrm{J}$ and Eneroth $\mathrm{M}$ : Costs of deep foot infections in patients with diabetes mellitus. Pharmacoeconomics 18: 225-238, 2000.

11. Ruan $\mathrm{H}$ and Dong LQ: Adiponectin signaling and function in insulin target tissues. J Mol Cell Biol 8: 101-109, 2016.

12. Zhang Y, He C, Qiu L, Wang Y, Qin X, Liu Y and Li Z: Serum unsaturated free fatty acids: A potential biomarker panel for early-stage detection of colorectal cancer. J Cancer 7: 477-483, 2016.

13. Stern JH, Rutkowski JM and Scherer PE: Adiponectin, leptin, and fatty acids in the maintenance of metabolic homeostasis through adipose tissue crosstalk. Cell Metab 23: 770-784, 2016.

14. Raskin P, Matfin G, Schwartz SL, Chaykin L, Chu PL, Braceras R and Wynne A: Addition of biphasic insulin aspart 30 to optimized metformin and pioglitazone treatment of type 2 diabetes mellitus: The ACTION Study (Achieving Control Through Insulin plus Oral ageNts). Diabetes Obes Metab 11: 27-32, 2009.

15. Mishra A, Guo Y, Zhang L, More S, Weng T, Chintagari NR, Huang C, Liang Y, Pushparaj S, Gou D, et al: A critical role for P2X7 receptor-induced VCAM-1 shedding and neutrophil infiltration during acute lung injury. J Immunol 197: 2828-2837, 2016.
16. Zhao ZH, Fan YC, Zhao Q, Dou CY, Ji XF, Zhao J, Gao S, Li XY and Wang K: Promoter methylation status and expression of PPAR- $\gamma$ gene are associated with prognosis of acute-on-chronic hepatitis B liver failure. Clin Epigenetics 7: 115, 2015.

17. De Simone V, Franzè E, Ronchetti G, Colantoni A, Fantini MC, Di Fusco D, Sica GS, Sileri P, MacDonald TT, Pallone F, et al: Th17-type cytokines, IL- 6 and TNF- $\alpha$ synergistically activate STAT3 and NF- $\kappa \mathrm{B}$ to promote colorectal cancer cell growth. Oncogene 34: 3493-3503, 2015.

18. Han SS, Kim DK, Kim S, Chin HJ, Chae DW and Na KY: C-reactive protein predicts acute kidney injury and death after coronary artery bypass grafting. Ann Thorac Surg 104: 804-810, 2017.

19. Ghiasi R, Ghadiri Soufi F, Mohaddes G, Alihemmati A, Somi MH, Ebrahimi H, Mirzaie Bavil F and Alipour MR: Influance of regular swimming on serum levels of CRP, IL-6, TNF- $\alpha$ in high-fat diet-induced type 2 diabetic rats. Gen Physiol Biophys 35: 469-476, 2016.

20. Parisi MCR, Moura Neto A, Menezes FH, Gomes MB, Teixeira RM, de Oliveira JEP, Pereira JRD, Fonseca RMC, Guedes LBA, Costa E Forti A, et al: Baseline characteristics and risk factors for ulcer, amputation and severe neuropathy in diabetic foot at risk: The BRAZUPA study. Diabetol Metab Syndr 8: 25, 2016.

This work is licensed under a Creative Commons Attribution-NonCommercial-NoDerivatives 4.0 International (CC BY-NC-ND 4.0) License. 